\title{
EFFICIENCY TESTING OF THERMOELECTRIC COOLING CELL BASED ON PELTIER MODULE
}

\author{
P. Kolber ${ }^{*}$, D. Perczyński* ${ }^{*}$ K. Peszyński* , B. Landowski*
}

\begin{abstract}
The paper presents preliminary studies on the effectiveness of a cooling cell based on the Peltier module. A TEC1-12707 type module was used in the test stand. The efficiency and performance of the cooling cell for different values of the power supply were analyzed. During the tests, the hot side was cooled by convection using an aluminum radiator. The tests were carried out on a specially prepared stand for this purpose.
\end{abstract}

\section{Keywords: Peltier effect, thermoelectric circuit, Joule heating, heat transfer, thermoelectric voltage}

\section{Introduction}

The Peltier circuit, the basic element of the cooling thermoelectric cell, consists of semiconductors p-type and n-type connected in series with copper plates. The copper plates, on both sides, are thermally bonded to each other through ceramic plates, but are electrically insulated. In terms of electricity, semiconductors are connected in series with each other, however with respect to thermal in parallel (Fig. 1).

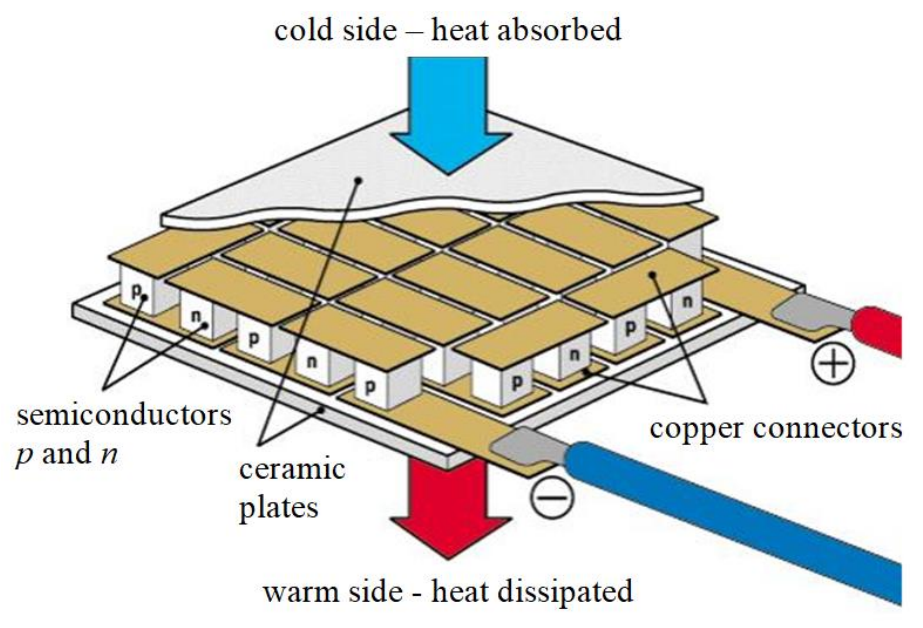

Fig. 1: Construction of the Peltier circuit.

Semiconductors are used instead of other conductive materials, e.g. metals, because among them are materials with a high-voltage thermoelectric, which conduct well current, but are thermal insulators. In this way, you can effectively isolate the cold side from the hot one thanks to which the appropriate temperature difference is obtained.

\footnotetext{
Assist. prof. Piotr Kober, PhD.,pkolber@utp.edu.pl

Assist. prof. Daniel Perczyński, PhD., daniel.perczynski@utp.edu.pl

Assoc. prof. Kazimierz Peszynski, PhD.,kazimierz.peszynski@utp.edu.pl

Assist. prof. Bogdan Landowski, PhD., bogdan.landowski@utp.edu.pl

All authors from UTP University of Science and Technology (Poland), Faculty of Mechanical Engineering, Al. prof. S. Kaliskiego 7, 85-796 Bydgoszcz; PL
} 
In the Peltier circuit, thermal energy, as a result of the current flow, is transferred from one side to the other, i.e. it is absorbed on cold side and emitted to the warmer plate. The warmer side must be able to dissipate heat to the environment. The direction of heat flow depends on the current direction. Peltier modules are used for cooling electronic components, e.g., processors, in medicine for cooling biological preparations, freezing of tissues, in portable refrigerators, in beer and wine coolers, etc. (Czaplicki A. et al., 2011).

\section{Power balance in the Peltier module}

The effect of Joule and the heat conduction have a significant influence on the operation of the Peltier module, in addition to the Peltier effect itself. The two above-mentioned additional phenomena have a negative effect on heat transport from one side to the other. The Seebeck and Thomson phenomena are still present during the tested module operation, but they play a less significant role and are usually omitted.

The power of heat flux for cold side $P_{c}$ and hot side $P_{h}$ in module is determined by the equations (Królicki Z., 2006)

$$
\begin{aligned}
& P_{c}=\alpha T_{c} I-\frac{1}{2} I^{2} R-K \Delta T \\
& P_{h}=\alpha T_{h} I+\frac{1}{2} I^{2} R-K \Delta T
\end{aligned}
$$

where:

$\alpha-$ Seebeck coefficient, $\mathrm{V} / \mathrm{K}$,

$I$ - current in the circuit, A,

$R$ - resistance of the circuit, $\Omega$,

$T_{c}, T_{h}$ cold and hot side temperatures, $\mathrm{K}$,

$K$ - thermal conductivity of the thermocouple, $\mathrm{W} / \mathrm{K}$,

$\Delta T=T_{h}-T_{c}, \mathrm{~K}$.

Based on the above equations, it can be concluded that the cooling efficiency of a thermoelectric device is influenced by such parameters as the current intensity, physical properties of the thermocouple material and its geometrical dimensions. Therefore, a good thermoelectric material should be characterized by: high electrical conductivity (low resistivity $\rho$ to limit Joule's heat), high Seebeck coefficient $\alpha$, so that a small temperature difference generates high voltage and low thermal conductivity to keep $K$ the heat on the joints and maintain a high temperature gradient. Therefore, there is a factor that characterizes a given material in terms of its suitability for building Peltier cells, so-called coefficient of thermoelectric goodness of the material (Królicka A. et al., 2012):

$$
Z=\frac{\alpha^{2}}{R \cdot K} \quad \frac{1}{\mathrm{~K}}
$$

The thermal flux power generated on the hot side of the thermocouple $P_{h}$ is the sum of the thermal flux power absorbed from the environment on the cold side $P_{c}$ and the supplied electrical power $P_{e}$. Therefore, the power balance equation is as follows:

$$
P_{h}=P_{e}+P_{c}
$$

Therefore, after subtracting from equation (2) equation (1) and entering $\Delta T=T_{h}-T_{c}$ a formula determining the electrical power supplied was obtained:

$$
P_{e}=P_{h}-P_{c}=\alpha I \Delta T+I^{2} R=U I
$$

Therefore, the cooling efficiency coefficient can be determined by:

$$
\varepsilon=\frac{P_{c}}{P_{e}}=\frac{\alpha T_{c} I-\frac{1}{2} I^{2} R-K \Delta T}{\alpha I \Delta T+I^{2} R}
$$




\section{Testing stand and tests implementation}

In the test stand was used the Peltier TEC1-12707 module with dimensions $40 \times 40 \times 3.6 \mathrm{~mm}$ and the following parameters: supply voltage $12 \mathrm{~V}(\max 15.4 \mathrm{~V})$, supply current $5 \mathrm{~A}$ (max. $7 \mathrm{~A}$ ), maximum power consumed $107.8 \mathrm{~W}$, maximum released power $62.2 \mathrm{~W}$, length of connecting cables $33 \mathrm{~cm}$, $\Delta T_{\max }=59^{\circ} \mathrm{C}, T_{\min }=-135^{\circ} \mathrm{C}$.

The test stand also included a laboratory power supply with voltage and current control. Measurements of the temperature values of the cold side $T_{\mathrm{c}}$ and hot side $T_{\mathrm{h}}$ of the module were made using the ARDUINO microcontroller and digital temperature sensors DS18B20 placed on the heat radiators attached to both sides of the module (Fig. 2). Measurements were saved every 5s on the SD memory card. Using the power supply device, the Peltier module power supply was controlled. Between the objects (radiators) located on both sides of the module, insulators in order to prevent direct heat exchange between them were placed. Additionally, insulators determined the position of the module. The ceramic walls of the Peltier module have been greased with thermal paste to provide better heat exchange between their surfaces and the surfaces of radiators adjacent to the module.

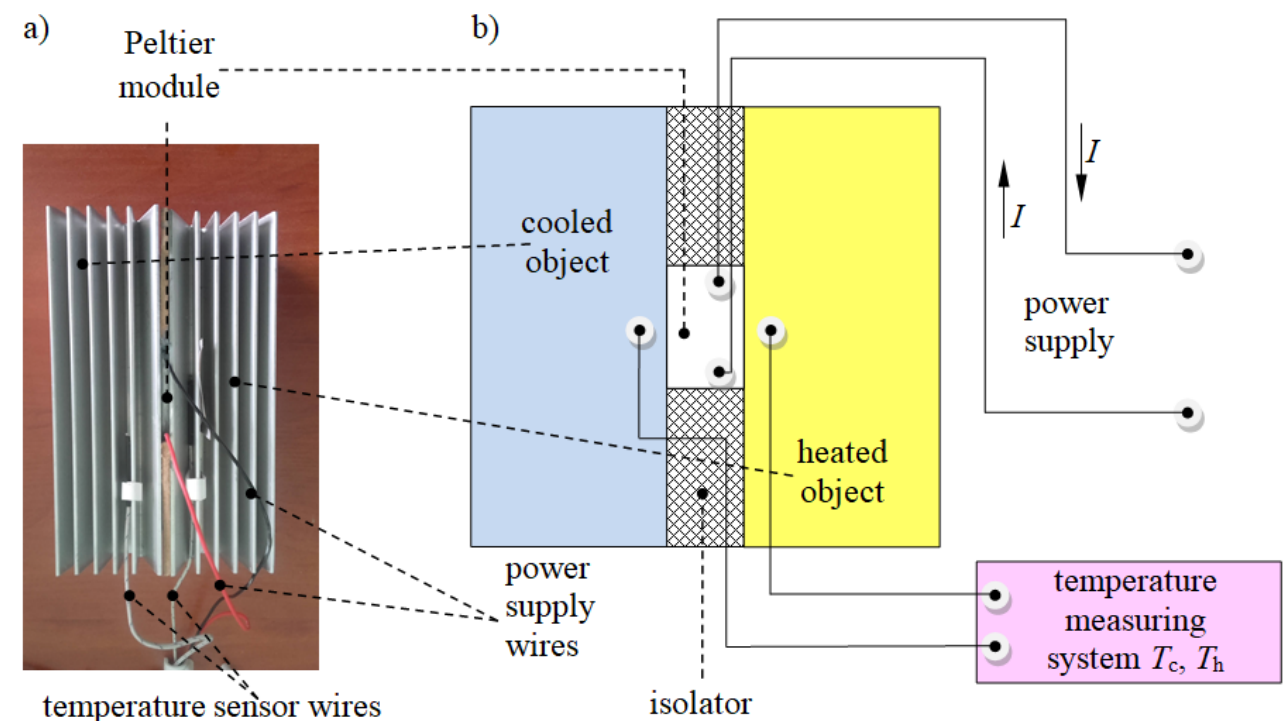

Fig. 2: Test stand: a) a photo of the basic part, b) scheme.

Recording of measurements started after establishing relatively even temperature values on both sides of the module and took place for a given value of the power supply.

Sample temperature charts on the cold side $T_{c}$ and hot $T_{h}$ for two values of power supply $P_{\text {e1 }}=7.1 \mathrm{~W}$ and $P_{\mathrm{e} 2}=40.2 \mathrm{~W}$ are shown in Fig. 3. Note that the temperature sensors were attached to the radiators (cooled and heated body) near the Peltier module (see Fig. 2).

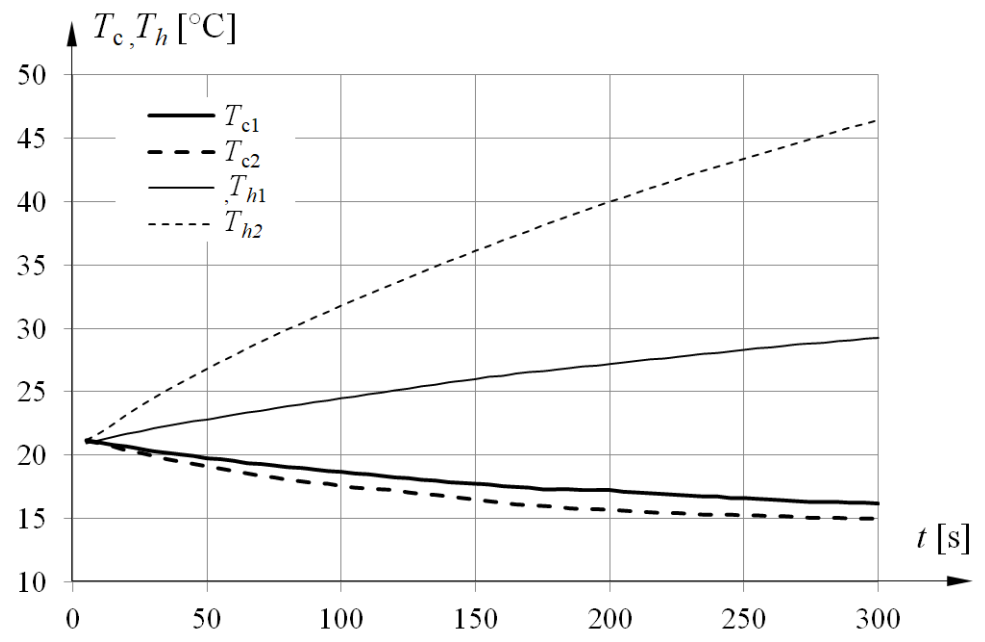

Fig. 3: Temperatures of the cooled and heated side near the Peltier module. 
On the basis of the straight-line initial sections of the cold side temperature curve as a function of time $T_{c}=f(t)$ and heat capacity of the refrigerated object, the power $P_{c}$ of cooling side and efficiency of the cooling cell $\eta_{c}$ based on the Peltier module was determined:

$$
\begin{gathered}
P_{c}=m \cdot c_{A l} \cdot \frac{\Delta T_{c}}{\Delta t} \\
\eta_{c}=\frac{P_{c}}{P_{e}}=\frac{P_{c}}{I \cdot U}
\end{gathered}
$$

where:

$m$ - the weight of the refrigerated object (radiator), $\mathrm{kg}$,

$c_{\mathrm{Al}}$ - specific heat of aluminum, $\mathrm{J} / \mathrm{kgK}$,

$I, U$ - current and supply voltage, $\mathrm{A}, \mathrm{V}$.

The values of power $P_{c}$ and efficiency $\eta_{c}$ of the cooling cell for given power supply values are shown in Fig. 4 and Fig. 5.

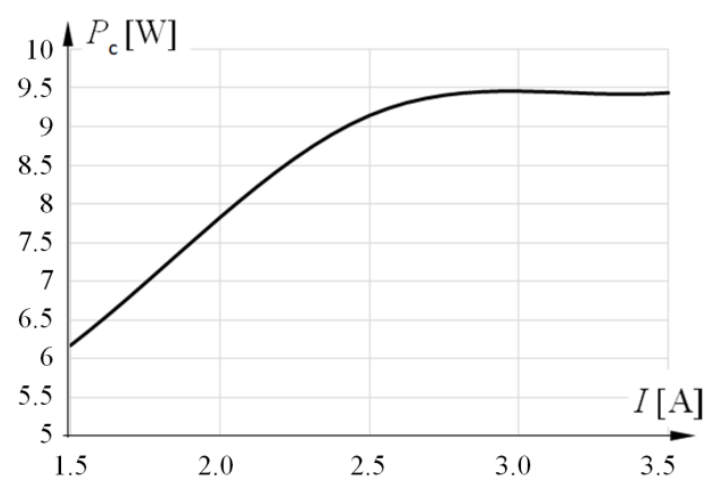

Fig. 4: Power of the cooling cell $P_{c}=f(I)$.

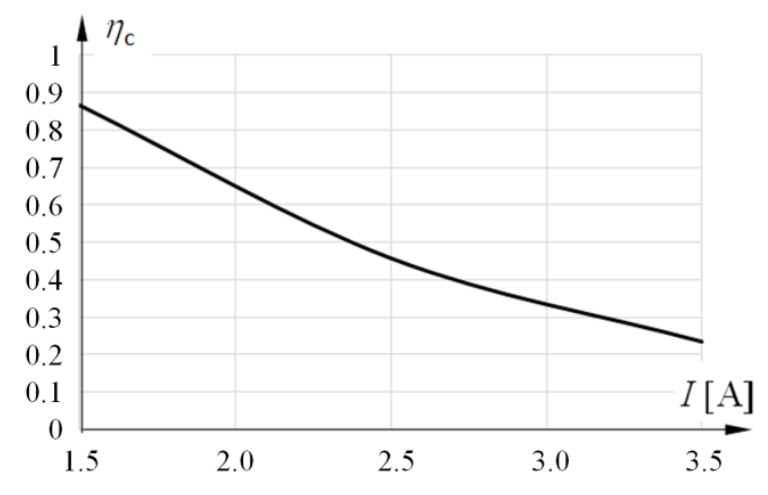

Fig. 5: Efficiency of the cooling cell $\eta_{c}=f(I)$.

\section{Conclusions}

Based on the research carried out on the cooling cell based on the Peltier module, it can be concluded that with the increase of the power supply value decreased its efficiency. This resulted mainly from the increase in Joule's heat emitted, which depends on the square of the current supplying the Peltier module. Another phenomenon that has a negative impact on the efficiency of the cooling cell is the phenomenon of thermal conductivity, the effect of which becomes greater as the temperature difference between the hot side and the cold side increases. The tested cell used cooling (heat dissipation) on the hot side by convection using an aluminum radiator. A positive effect on increasing the efficiency of the cooling cell would be the use of hot side additional forced cooling through a fan or water cooling. Next tests will be carried out at a stand in which the cold side will be at least partially separated from the direct influence of heat from the environment.

\section{Acknowledgement}

Authors received institutional support BS 16/2013 granted by Faculty of Mechanical Engineering of UTP University.

\section{References}

Czaplicki A., Niedbała R., Wesołowski M. (2011) Temperature chamber based on Peltier modules. Przegląd Elektrotechniczny (Electrical Review), ISSN 0033-2097, R.87 Nr 7/2011 (in Polish).

Królicka A., Hruban A., Mirowska A. (2012) Modern thermoelectric materials - a literature review. Materiały elektroniczne (Electronic Materials), T.40, Nr 4/2012 (in Polish).

Królicki Zb. (2006) Basics Thermodynamic of temperature reduction. Oficyna wydawnicza Politechniki Wrocławskiej, Wrocław 2006 (in Polish). 